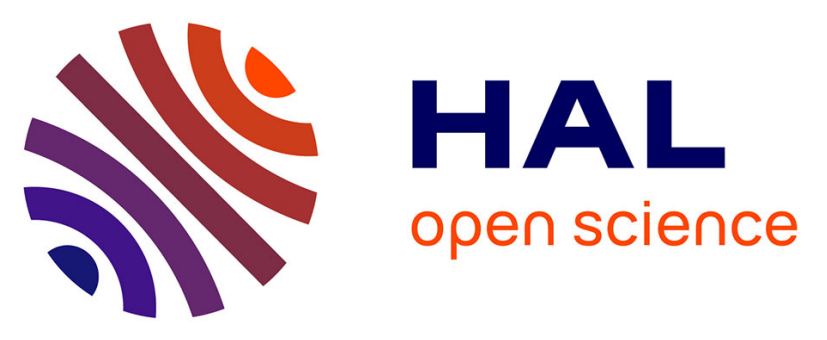

\title{
Development of an attrition-leaching hybrid process for direct aqueous mineral carbonation
}

Carine Julcour-Lebigue, Florent Bourgeois, Benjamin Bonfils, Imane Benhamed, François Guyot, Françoise Bodénan, Charlotte Petiot, Éric C. Gaucher

\section{To cite this version:}

Carine Julcour-Lebigue, Florent Bourgeois, Benjamin Bonfils, Imane Benhamed, François Guyot, et al.. Development of an attrition-leaching hybrid process for direct aqueous mineral carbonation. Chemical Engineering Journal, 2015, 262, pp.716-726. 10.1016/j.cej.2014.10.031 . hal-01356854

\section{HAL Id: hal-01356854 https://hal-brgm.archives-ouvertes.fr/hal-01356854}

Submitted on 20 May 2019

HAL is a multi-disciplinary open access archive for the deposit and dissemination of scientific research documents, whether they are published or not. The documents may come from teaching and research institutions in France or abroad, or from public or private research centers.
L'archive ouverte pluridisciplinaire $\mathbf{H A L}$, est destinée au dépôt et à la diffusion de documents scientifiques de niveau recherche, publiés ou non, émanant des établissements d'enseignement et de recherche français ou étrangers, des laboratoires publics ou privés. 


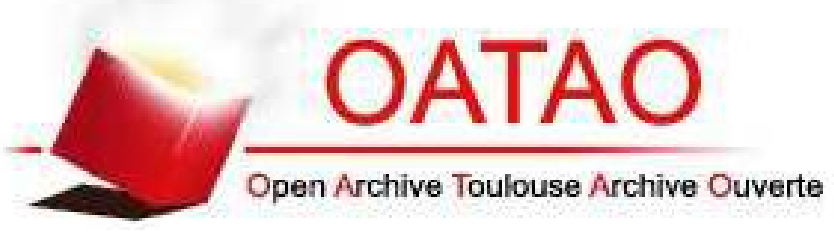

\section{Open Archive Toulouse Archive Ouverte (OATAO)}

OATAO is an open access repository that collects the work of some Toulouse researchers and makes it freely available over the web where possible.

This is an author's version published in: http://oatao.univ-toulouse.fr/20828

Official URL: https://doi.org/10.1016/j.cej.2014.10.031

\section{To cite this version:}

Julcour-Lebigue, Carine and Bourgeois, Florent and Bonfils, Benjamin and Benhamed, Imane and Guyot, François and Bodénan, Françoise and Petiot, Charlotte and Gaucher, Eric Development of an attrition-leaching hybrid process for direct aqueous mineral carbonation. (2014) Chemical Engineering Journal, 262. 716-726. ISSN 1385-8947

Any correspondence concerning this service should be sent to the repository administrator: tech-oatao@listes-diff.inp-toulouse.fr 


\title{
Development of an attrition-leaching hybrid process for direct aqueous mineral carbonation
}

\author{
Carine Julcour $^{\mathrm{a}, \mathrm{b}}$, Florent Bourgeois ${ }^{\mathrm{a}, *}$, Benjamin Bonfils ${ }^{\mathrm{a}}$, Imane Benhamed ${ }^{\mathrm{a}}$, François Guyot ${ }^{\mathrm{c}}$, \\ Françoise Bodénan $^{\mathrm{d}}$, Charlotte Petiot ${ }^{\mathrm{e}}$, Éric C. Gaucher ${ }^{\mathrm{f}}$ \\ a Université de Toulouse, Laboratoire de Génie Chimique, Toulouse, France \\ ${ }^{\mathrm{b}}$ CNRS, Laboratoire de Génie Chimique, Toulouse, France \\ ' Institut de Minéralogie et de Physique des Milieux Condensés (IMPMC), UMR 7590 CNRS, MNHN, UPMC, IRD, Paris, France \\ ¿ BRGM, Orléans, France \\ e Bio Intelligence Services, Paris, France \\ ${ }^{\mathrm{f}}$ Centre Scientifique et Technique Jean Feger, TOTAL, Pau, France
}

\section{H I G H L I G H T S}

- Attrition leaching, a new hybrid process for direct aqueous mineral carbonation.

- Hybrid process yields continuous mechanical exfoliation of passivation layer.

- Proven synergy between mechanical exfoliation and mineral carbonation.

- Hybrid process yields up to $80 \%$

carbonation in $24 \mathrm{~h}$.

- Robustness of the hybrid process towards variations in ore type.

\section{Keywords:}

Direct aqueous mineral carbonation

Magnesium silicates

Attrition

Leaching

Stirred bead mill
G R A P H I C A L A B S T R A C T

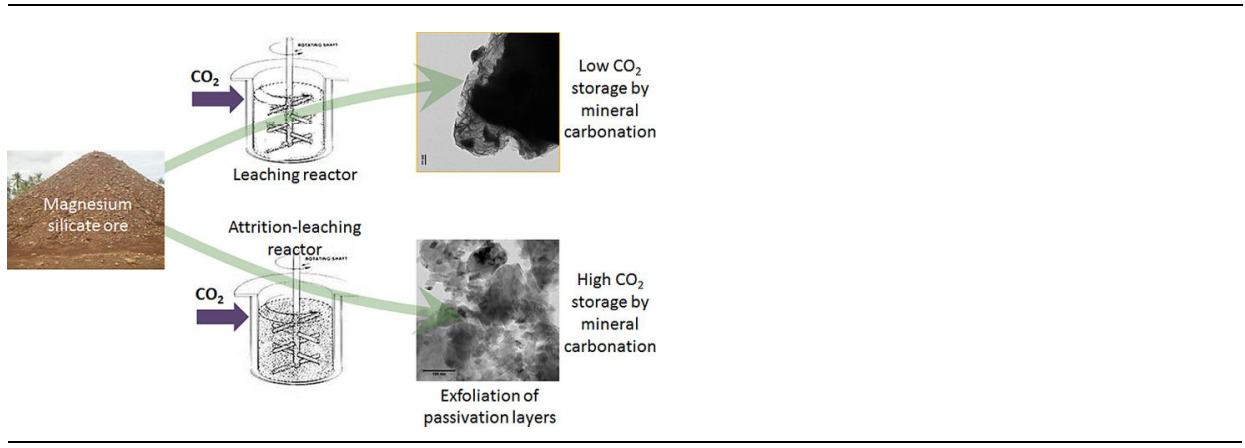

A B S T R A C T

Mineral carbonation is the single most eligible companion solution to geosequestration for mitigation of anthropic $\mathrm{CO}_{2}$ emissions on a large scale. Amongst its possible pathways, direct aqueous mineral carbonation stands out as one of the most promising ones. The originality of the present work lies in the transposition of the concomitant exfoliation/mineralisation concept, which was first proposed by the mineral carbonation research group from the Arizona State University in early 2000s, inside a dedicated attrition environment, more specifically inside a stirred bead mill. Experimental results and analyses bring definite proofs about the possibility and synergy of concomitant exfoliation and mineralisation. Given high carbonation yield for olivine and serpentinised ores (up to 35\% in $5 \mathrm{~h}$ and $80 \%$ in $24 \mathrm{~h}$ in water, and $70 \%$ in $5 \mathrm{~h}$ with inorganic additives) and the capacity of stirred mills to process mining size throughputs, this work leads to real perspectives for developing large scale robust solutions for direct aqueous mineral carbonation.

\footnotetext{
* Corresponding author. Tel.: +33 534323633.

E-mail address: florent.bourgeois@ensiacet.fr (F. Bourgeois).
} 


\section{Introduction}

\subsection{Generalities about mineral carbonation}

Alongside geological storage, a number of complementary $\mathrm{CO}_{2}$ mitigation solutions have been proposed and investigated, particularly since the mid-nineties. Mineral carbonation, which consists in binding $\mathrm{CO}_{2}$ as chemically inert mineral carbonate, has been identified as one such solution for two decades already [1,2]. This process, which is about accelerating the otherwise slowly naturally occurring silicate weathering process [3], produces carbonates and other products that are environmentally benign under ambient conditions, hence it offers $\mathrm{CO}_{2}$ storage permanency. Because carbonatable materials, mainly magnesium silicates, are plentiful on Earth, often outcropping, mineral carbonation is acknowledged as a medium to large scale solution for $\mathrm{CO}_{2}$ sequestration. Acceptability from land use and other competitive interests, food security in particular, does not appear to be a prohibitive issue considering the widespread and geolocalisation of carbonatable minerals. Industrial Mg- or Ca-bearing wastes [4], such as slags [5], red mud [6], mining wastes [7,8], fly ash [9] and desalination brines [10] also offer early opportunities for mineral carbonation; however alkaline industrial wastes represent an annual sequestration potential less than $1 \%$ of the worldwide emissions [11]. Therefore natural carbonatable minerals represent the only sensible target for development and deployment of mineral carbonation.

Long relegated to the immature or "niche" category, mineral carbonation is now accepted as an eligible companion solution to geosequestration for $\mathrm{CO}_{2}$ mitigation, and is currently met with actual pilot-scale demonstration projects, like the GreenMagNewcastle program [12,13].

\subsection{The direct aqueous mineral carbonation process: state-of-the-art and issues}

Amongst the various mineral carbonation routes that are being investigated [14], direct aqueous mineral carbonation is possibly the most promising one. Pioneering studies from Albany Research Center (now NETL-Albany) reported carbonation yields as high as $78 \%$ in $30 \mathrm{~min}$ for serpentine particles with inorganic additives [15]. However their process suffers strong energy penalties due to the prior dehydration of the serpentine materials at 600$650^{\circ} \mathrm{C}$, the fineness of the feed particle size distribution $\left(d_{50}\right.$ less than $10 \mu \mathrm{m} \mathrm{[16]),} \mathrm{and} \mathrm{the} \mathrm{severe} \mathrm{operating} \mathrm{conditions}\left(155^{\circ} \mathrm{C}\right.$ and total $\mathrm{CO}_{2}$ pressure of $185 \mathrm{~atm}$ ). Further work from Arizona State University team [17-19] not only aimed at reducing these penalties, but also focused on local reaction mechanisms, bringing evidence of the formation of amorphous silica-rich passivation layers on the surface of Mg-bearing silicates during carbonation. Such mechanism has been recognised for a long time however, during natural weathering under oxidizing conditions [20]. Still, both the formation mechanisms of amorphous silica layers [21,22] and their transport properties [23] remain the subject of some controversy. The nature of the passivation layer depends on many factors, including the structure and the chemical composition of the substrate particles [24], the density of the mineral phase that makes up the passivation layer, and the temperature of carbonation. As an illustration, Fig. 1 from our previous work [25] shows the products obtained from $-100 \mu \mathrm{m}$ olivine particles, carbonated in water only, i.e. without additives. An operating temperature of $180{ }^{\circ} \mathrm{C}$ led to the formation of a covering silica iron oxide-rich layer some 20$30 \mathrm{~nm}$ thick, totally impervious, against that of a micrometer thick phyllosilicate layer at $120^{\circ} \mathrm{C}$. The nano-thick layer passivated the silicate surface resulting in no measurable carbonate formation, whereas the micron-thick one, possibly less impervious and/or covering, gave a few percent carbonation yield in $24 \mathrm{~h}$. Such complexity casts serious doubts about the possibility of developing robust chemistry-based solutions, given the great many variety of ore types to be processed and the sensitivity of passivation layers to mild changes in operating conditions.

What springs to mind is to attack the problem from a different direction, moving away from trying to adapt the chemistry to the ore. It is also important to note that chemical solutions often imply consumption of additives, which are not always recyclable and often synonymous with added costs and potential environmental impacts.

\subsection{Introduction to the hybrid aqueous mineral carbonation process}

McKelvy et al. also attempted to deliberately exfoliate the passivation layer mechanically [18], as an alternative to depassivation using chemical additives. Their implementation consisted in (i) applying sonication to the particles and (ii) adding quartz particles of the same size as the reactive olivine particles to promote physical abrasion of the passivation layer. Tests were carried out in a stirred reactor, at $185^{\circ} \mathrm{C}$ and 150 bar of $\mathrm{CO}_{2}$ with the $\mathrm{ARC}$ standard $1 \mathrm{M} \mathrm{NaCl}+0.64 \mathrm{M} \mathrm{NaHCO}_{3}$ solution. If sonication $(20 \mathrm{kHz}, 600-$ $1500 \mathrm{~W})$, performed at mid-experiment, did not lead to any signif-
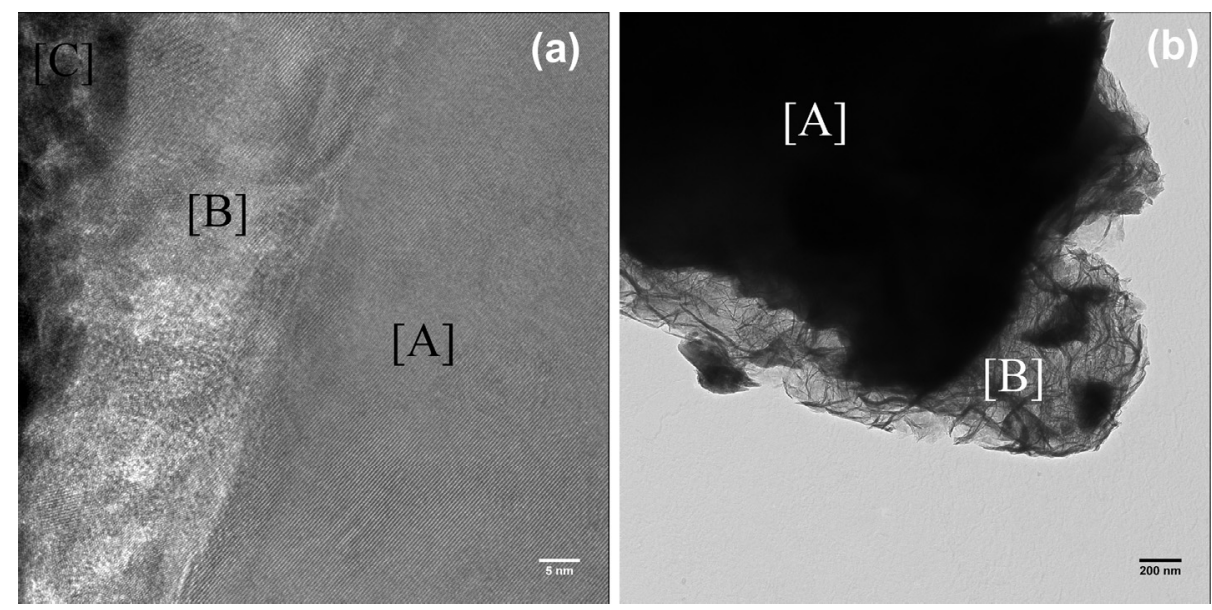

Fig. 1. Examples of silica-rich passivation layers forming at the olivine particle surface during direct aqueous mineral carbonation caption (Bodénan et al. [28]). (a) TEM image zooming on the cross-section of the olivine particle surface after $24 \mathrm{~h}$ at $120{ }^{\circ} \mathrm{C}$ (slurry solid concentration: $3 \mathrm{~g} \mathrm{~L}^{-1} ; \mathrm{PCO}_{2}: 20 \mathrm{bar}$ ): [A] residual olivine, [B] layer made of iron oxide and silica, $[\mathrm{C}]$ traces of gold from surface metal deposition for making of the thin section by FIB. Scale indicator $=5 \mathrm{~nm}$. (b) TEM image of olivine particle surface after $95 \mathrm{~h}$ at $180{ }^{\circ} \mathrm{C}$ (slurry solid concentration: $90 \mathrm{~g} \mathrm{~L}^{-1} ; \mathrm{PCO}_{2}: 20 \mathrm{bar}$ ): [A] residual olivine, [B] magnesium phyllosilicate layer. Scale indicator $=200 \mathrm{~nm}$. 
icant improvement, addition of abrasive particles into the carbonation reactor yielded promising results. After $1 \mathrm{~h}$, they obtained a rise in extent of carbonation from $68 \%$ without abrasive to $84 \%$ for a feed bearing $60 \mathrm{wt} \%$ abrasive particles. Using more than $60 \mathrm{wt} \%$ silica particles led to a drop in extent of carbonation, which they interpreted as silica self-abrasion reducing its effectiveness as an olivine exfoliation agent. They also confirmed that this exfoliation was effective over a range of temperatures and pressures.

Similarly, Park and Fan [26-29] tested ultrasounds, acoustic and internal grinding to remove the diffusion limiting silica layer, whose hindering effect they reported in their 2003 work [26]. However they were interested in a $\mathrm{pH}$-swing process instead of direct aqueous carbonation, so they applied different grinding media for the dissolution phase that was carried out in a fluidized bed reactor under ambient conditions. They concluded that glass beads were the most effective at refreshing passivated serpentine surfaces and that combination of internal grinding and Mg-leaching solvent yielded rapid serpentine dissolution. Their approach also differed from that of ASU regarding the size of the grinding media, as they used $2-5 \mathrm{~mm}$ beads to exfoliate $-75 \mu \mathrm{m}$ serpentine particles. They argued that the ASU's results were simply due to particle size reduction, whereas their technological choice would meet the intended objective of refreshing surfaces rather than creating new unpassivated surfaces through particle fracture. Actually, the fact that the ARC/ASU test work led to $2 \mu \mathrm{m}$ particles in the end product [30] must be, at least partly due to their conducting exfoliation and mineralisation concomitantly, which Park and Fan did not achieve given the nature of the pH-swing process. The technological soundness of Park and Fan's fluidized bed solution is also difficult to assess, if one takes the sheer quantity of material to be processed.

Be as it may, there is evidence from the existing literature that mechanical exfoliation of passivating layers is one avenue which, if successful, would confer mineral carbonation a desirable robustness with respect to the variability of ore type and operating conditions. The present work took the position that ASU's results were mitigated by the fact that they did not implement the coupled exfoliation/mineralisation concept in efficient enough an exfoliation environment. In our earlier contribution [25], we have summarised the excellent carbonation yields that were obtained by operating the direct aqueous mineral carbonation process inside a dedicated attrition environment, more specifically inside a stirred bead mill.

The present paper serves to give a full and detailed account of the process itself, which involves coupling attrition and leaching for mineral carbonation, and discusses the driving mechanisms. Such an innovative hybrid process is referred to as "attritionleaching", whereby leaching of the ore is carried out inside an attrition mill for the purpose of continuous elimination of leached passivation layers. The work brings definite proofs about the synergy of concomitant mechanical exfoliation and mineralisation. Included in the present paper is a preliminary life cycle assessment analysis of this innovative process, with implication for process optimisation. Given the capacity of stirred bead mills to process mining size throughputs, this work opens real perspectives for developing large scale robust solutions for direct aqueous mineral carbonation.

The authors point out that the value of such a process extends beyond that of mineral carbonation, in that it could find applications in hydrometallurgical treatment of ores and wastes, for which leaching is recurrently hampered by surface passivation issues.

\section{Materials and methods}

\subsection{Experimental rationale and set-up}

Stirred bead mills, of which a number of commercial versions can be found [31] have a number of attributes which make them particularly suited for exfoliation purpose in the context of direct aqueous mineral carbonation. These include [31, 32,33]:

- scalability from small scale (a few litres) experiments, through tip speed or grinding media stress intensity;

- engineering maturity for large scale continuous operations, with typical feed flow rates set points about $200 \mathrm{~m}^{3} \mathrm{~h}^{-1}$ for large units in operation, at high slurry density. Typical slurry solid concentration used in this work is $90 \mathrm{~g} \mathrm{~L}^{-1}$ or about $9 \mathrm{wt} \%$, but this type of equipment can operate in the field at $40 \mathrm{wt} \%$ and higher;

- energy efficiency for particle abrasion with $-100 \mu \mathrm{m}$ feed typically, but with possibility to extend to coarser feed, say $-2 \mathrm{~mm}$; - possibility to use low cost natural grinding medium, such as silica, with the interesting possibility of autogenous grinding mode;

- feasibility of modifying existing designs to sustain the pressure and temperature conditions demanded by direct aqueous mineral carbonation through material selection, and to allow continuous $\mathrm{CO}_{2}$ gas injection and dispersion.

In the context of this work, a $300 \mathrm{~mL}$ stirred autoclave reactor was modified and used as a high pressure high temperature stirred bead mill. Photographs of the set-up are given in Fig. 2. The set-up permitted conducting direct aqueous mineral carbonation experiments in batch mode, under controlled temperature and pressure conditions, with and without concomitant attrition depending on

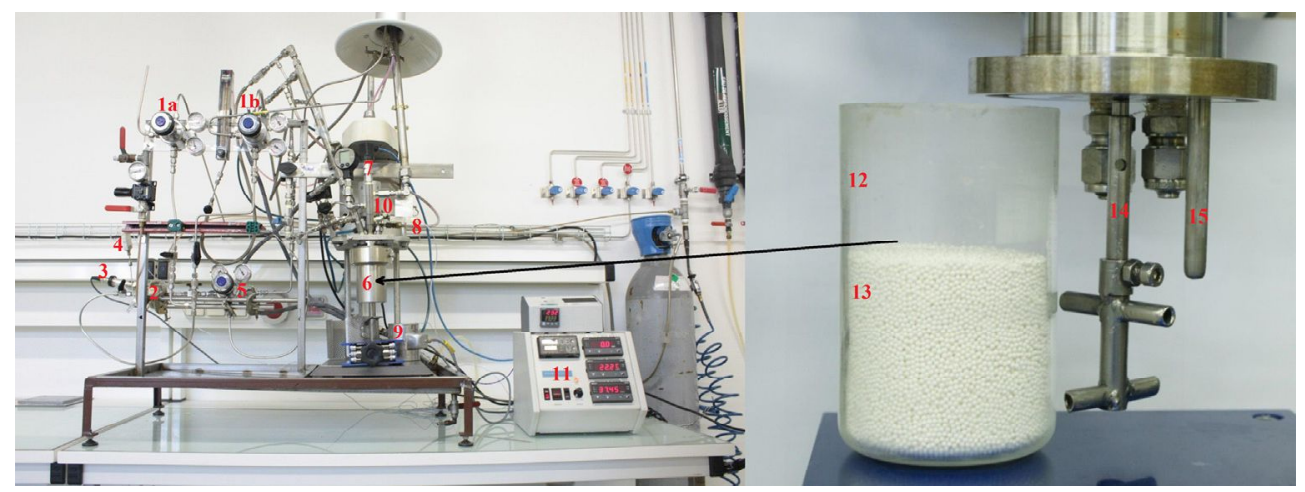

Fig. 2. Overview of the attrition-leaching set-up and close-up view of the attrition chamber with alumina beads. 1 gas line equipped with pressure regulation valve (a $\mathrm{N}_{2}$, $\mathrm{b}$ $\mathrm{CO}_{2}$ ), 2 gas reservoir, 3 pressure transducer, 4 Pt-100 probe, 5 pressure regulation valve, 6300 mL Hastelloy reactor, 7 pressure transducer, 8 Pt-100 probe, 9 furnace, 10 magnetic drive, 11 control and monitoring panel, 12 glass inner jacket, 13 grinding media, 14 attrition/gas dispersion stirrer, 15 thermowell. 
Table 1

Chemical composition of the five ores selected for this work (Bodénan et al. [28]).

\begin{tabular}{llllll}
\hline & $\begin{array}{l}\text { Olivine } \\
\text { (wt\%) }\end{array}$ & $\begin{array}{l}\text { Harzburgite } \\
\mathrm{Hz1}(\text { wt\%) }\end{array}$ & $\begin{array}{l}\text { Harzburgite } \\
\mathrm{Hz2}(\text { wt\%) }\end{array}$ & $\begin{array}{l}\text { Lherzolite } \\
\text { (wt\%) }\end{array}$ & $\begin{array}{l}\text { Wehrlite } \\
\text { (wt\%) }\end{array}$ \\
\hline $\mathrm{SiO}_{2}$ & 42.2 & 40 & 39.3 & 46.3 & 44.6 \\
$\mathrm{MgO}$ & 46.4 & 41.1 & 40.4 & 30.8 & 32.0 \\
$\mathrm{Fe}_{2} \mathrm{O}_{3}$ & 9.8 & 7.8 & 7.3 & 7.6 & 7.5 \\
$\mathrm{Al}_{2} \mathrm{O}_{3}$ & 0.5 & 0.6 & 1.3 & 4.0 & 3.7 \\
$\mathrm{CaO}$ & 0.2 & 0.6 & 0.9 & 5.0 & 4.9 \\
$\mathrm{MnO}$ & 0.1 & 0.12 & 0.1 & 0.15 & 0.14 \\
$\mathrm{Na}_{2} \mathrm{O}$ & 0.2 & $<0.2$ & $<0.2$ & $<0.2$ & $<0.2$ \\
$\mathrm{~K}_{2} \mathrm{O}$ & 0.02 & $<0.05$ & $<0.05$ & $<0.05$ & $<0.05$ \\
$\mathrm{TiO}_{2}$ & 0.008 & $<0.05$ & $<0.05$ & $<0.05$ & $<0.05$ \\
$\mathrm{Total} \mathrm{C}^{\text {Loss on ignition }}$ & 0.04 & 0.11 & 0.10 & 0.12 & $<0.1$ \\
at $1000{ }^{\circ} \mathrm{C}$ & 0.1 & 9.1 & 10.4 & 5.7 & 6.2 \\
& & & & &
\end{tabular}

whether grinding media would be used. The $\mathrm{CO}_{2}$ pressure inside the reactor was regulated using a $\mathrm{CO}_{2}$ ballast tank and gas pressure regulator, and instantaneous $\mathrm{CO}_{2}$ consumption by the liquid-solid suspension was monitored by recording temperature and pressure inside the ballast. Slurry temperature was monitored and PID controlled.

When operating in hybrid attrition-leaching mode, the stirred reactor was filled with 30 vol.\% of $1.3 \mathrm{~mm}$ diameter alumina beads. Nominal test conditions used $90 \mathrm{~g} \mathrm{~L}^{-1}$ suspensions with -100 microns feed material. Different ores were tested during this work, whose characteristics are reported in Table 1 . The mechanical stirrer was rotated at moderate speed $(800 \mathrm{rpm})$ to promote attrition grinding. Dispersion of $\mathrm{CO}_{2}$ was achieved by feeding the gas through the stirrer hollow tubing for efficient gas-liquid mass transfer. A glass jacket, shown on the right handside of Fig. 2, was used to prevent reactor wear.

\subsection{Materials}

Five materials were used in this study. The first one, referred to as olivine, is produced by Magnolithe $\mathrm{GmbH}$ (Austria) and is mainly forsteritic olivine. The value of this particular mineral is that it has undergone heating at $1000^{\circ} \mathrm{C}$; hence it no longer contains structural water, which simplifies estimation of formed carbonates by thermogravimetric analysis (TGA). The other four materials are natural peridotites, with two harzburgites and wehrlite from New-Caledonia, and lherzolite from the French Pyrenees. Table 1 gives the chemical composition of these materials. Their mineralogical characteristics can be found in Bodénan et al. [25].

The ores were dry ground in a jar mill, which was operated to produce $-100 \mu \mathrm{m}$ feed material for mineral carbonation testing. The size distribution of these resulting materials is given in Fig. 3.

\subsection{Experimental protocols}

For the sake of this study, three distinct experimental protocols were used.

- Reference mode: This protocol produces the reference carbonation performance against which the other protocols are gauged. The slurry, consisting of ultra-pure water (or inorganic additive solution) and the investigated material, was prepared in a glass jar. After the jar was placed inside the autoclave, the reactor was purged several times with nitrogen under stirring to remove oxygen both from headspace and in solution. The ballast was filled with $\mathrm{CO}_{2}$ to about 45 bar, enough to ensure full carbonation of the material in the operating

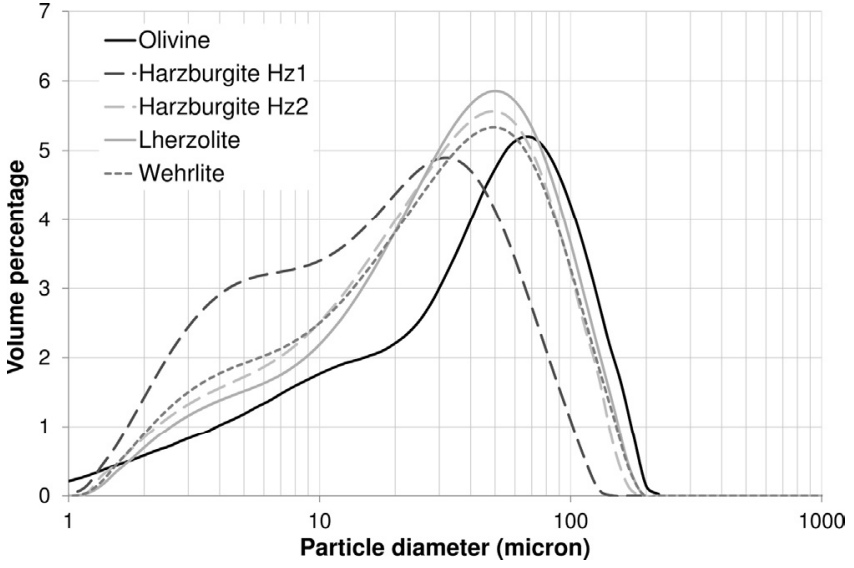

Fig. 3. Particle size distribution of the five materials, measured by laser granulometry (Mastersizer 2000)

conditions. Data acquisition was then started, with a sampling frequency of $1 \mathrm{~Hz}$. The slurry was heated under stirring up to the set temperature $\left(120^{\circ} \mathrm{C}\right.$ or $\left.180^{\circ} \mathrm{C}\right)$, which was reached after about half an hour. Subsequently, the stirring was stopped and $\mathrm{CO}_{2}$ was introduced into the reactor so that to reach a partial pressure of 20 bar (accounting for partial pressures of nitrogen and water vapour at the considered temperature). Note that this pressure value was mainly chosen for comparison purposes with the open literature $[18,34,35]$. After stabilization of pressure and temperature in the ballast and in the reactor (after about $1 \mathrm{~min}$ ), the stirring was started again (800 rpm) and the system was let on reacting for $24 \mathrm{~h}$ to highlight the differences in between this mode and the two-step mode, which both yield fast initial carbonation kinetics due to the fineness of the resulting particle size distribution. Nevertheless the monitoring of instantaneous gas consumption gave access to the whole reaction kinetics. At the end of the reaction, the acquisition was stopped and the slurry was cooled down to $60^{\circ} \mathrm{C}$ (still under stirring). Pressure was released and the slurry was transferred into a $1 \mathrm{~L}$ beaker and weighed. The reactor internals were thoroughly cleaned with osmosed water to recover stuck solid particles. The rinse solution was weighed and put into the beaker. The resulting slurry was passed through a $0.2 \mu \mathrm{m}$ micropore filter. The filtrate was analysed by ICP-AES and the solid was oven dried at $70^{\circ} \mathrm{C}$ during $24 \mathrm{~h}$ before weighing and analysis.

- Two-step mode: $300 \mathrm{~g}$ of alumina or zirconia beads (1.3 and $1 \mathrm{~mm}$ diameter, respectively), ultra-pure water and the investigated material were introduced in the glass jar, which was placed inside the autoclave. The reactor was purged several times with nitrogen while stirring to remove oxygen both from the headspace and the solution. The stirring speed was set to $800 \mathrm{rpm}$ and the attrition step was pursued during $24 \mathrm{~h}$ at room temperature, the reactor being immersed into a thermostated bath to prevent temperature rise due to the friction of the grinding media. Thereafter the reactor content was transferred into a $1 \mathrm{~L}$ beaker. The reactor internals were carefully cleaned with ultra-pure water to recover stuck solid particles. The mixture of slurry and grinding media was passed through a $0.8 \mathrm{~mm}$ sieve to separate the millimetre beads from the fine slurry. The beads were thoroughly rinsed with ultra-pure water to recover more solid. The diluted slurry was centrifuged at $200 \mathrm{~g}$ and $25{ }^{\circ} \mathrm{C}$ for $15 \mathrm{~min}$. After centrifugation, the clear supernatant was removed, the wet solid was reintroduced in the glass jar and water was added so that to almost match the previous slurry concentration. The glass jar was placed in the reactor 
and the carbonation step was then performed as described for the reference mode. After filtration, the solid product was also analysed for particle size distribution.

- Hybrid attrition-leaching mode: The reaction proceeded as described in the reference protocol, except that the grinding media was introduced in the glass jar along with the reactant suspension. After $24 \mathrm{~h}$ of carbonation under attrition, the fine slurry was separated from the millimetre beads as described for the two-step mode (using a $0.8 \mathrm{~mm}$ sieve and a careful rinse of the beads, all contents being weighed at each step). The resulting slurry was passed through a $0.2 \mu \mathrm{m}$ micropore filter and analysed for liquid and solid phases.

\subsection{Extent of carbonation}

The extent of carbonation is defined as the fraction of $\mathrm{Mg}$ and $\mathrm{Ca}$ from the initial feed material which is included into solid carbonates. The amount of solid carbonates formed by mineralisation is calculated by measuring the carbon content of the treated ores, accounting for the presence of carbonate in the initial ore (however negligible in most cases, see Table 1 ). Thermogravimetry analyses were also performed to confirm these results, but not retained for final calculations, as residual silicates (with the exception of olivine) contain structural water which is released within the same temperature range as formed carbonates $\left(300-600{ }^{\circ} \mathrm{C}\right)$.

From the final amount of carbonates, the evolution of the carbonation yield can be backtracked all the way to the very start of the process from the instantaneous $\mathrm{CO}_{2}$ consumption record, including the reactor headspace filling stage. It is then checked that this starting point matches with the beginning of steady pressure inside the reactor. Instantaneous carbonation yield is estimated by application of the Peng-Robinson state equation, using the temperature and pressure measured inside the $\mathrm{CO}_{2}$ ballast tank that feeds the system.

$\mathrm{CO}_{2}$ dissolution and precipitation of carbonates can occur simultaneously at the start of the application of $\mathrm{CO}_{2}$ to the system, making identification of the initial carbonation kinetics difficult. As expected, this difficulty was highest when using finely ground particles in two-step processing mode, the high initial particle surface area yielding very fast initial dissolution and carbonation kinetics.

\subsection{Water analyses and characterisation of solid phase}

After filtration of the entire reaction product using a $0.2 \mu \mathrm{m}$ micropore filter, the liquid phase was analysed on an Ultima 2 ICP-AES spectrometer (Horiba Jobin Yvon) to determine the amount of dissolved elements ( $\mathrm{Mg}$, $\mathrm{Si}, \mathrm{Fe})$.

Carbon content of the solid product was measured on a Perkin Elmer 2400 CHNS elemental analyser, using about $2 \mathrm{mg}$ of powder. For carbonation yields higher than 5\%, elemental analyses were replicated three or four times using separate samplings and showed less than $5 \%$ relative variation.

Thermograms were obtained on a Q600 apparatus (TA Instruments).

Apart from carbon and thermogravimetric analyses, the solid phase was characterised by scanning electron microscopy (SEM), using a Zeiss Ultra 55 FEG microscope operated at $10 \mathrm{kV}$ and a working distance of $7.5 \mathrm{~mm}$, and equipped with an energy dispersive X-ray (EDX) system from Bruker. Transmission electron microscopy (TEM) was also performed either on powders dispersed on carbon film or on thin sections prepared by a focused ion beam (FIB), using a Jeol FEG $2100 \mathrm{~F}$ operated at $200 \mathrm{kV}$ and equipped with an energy dispersive X-ray system from Jeol. Laser granulometry was used to determine particle size distribution: the measurement was made in wet mode on Mastersizer 2000 apparatus (Malvern Instruments), using a Hydro 2000S dispersion unit (stirring at $1750 \mathrm{rpm}$ ).

\section{Results and analysis}

\subsection{Benchmarking process performance}

As with any process development, it is always necessary to rate the performance obtained under given process conditions against a reference or a set of objectives. Here, we predicted the change in extent of carbonation with time as if the material remained unpassivated throughout the test, i.e. through a shrinking particle model which used a dissolution rate law established for fresh ore surface [36]. This gave the best achievable kinetics for olivine carbonation under given operating conditions. As the process is controlled by the chemical reactions that occur at the particle surface, the actual particle size distribution of the olivine feed has to be accounted for. The particle size analysis, measured by laser diffraction, was first converted from a volume distribution to an areal distribution. This distribution was then divided into 20 size classes, each class contributing $5 \%$ of the areal distribution. Each size class was entered into the geochemical code Chess [37] as a distinct material, albeit with the same thermodynamic properties (from CTDP database entry forsterite $\mathrm{Mg}_{2} \mathrm{SiO}_{4}$ ) but with distinct specific surface area. This modelling approach was used to predict the lixiviation kinetics with good precision [38].

The example from Fig. 4 compares the measured reference experiment with no grinding medium and the best achievable performance for a $90 \mathrm{~g} \mathrm{~L}^{-1}$ suspension of olivine in water, at a temperature of $180^{\circ} \mathrm{C}$ and a $\mathrm{CO}_{2}$ partial pressure of 20 bar.

The most striking feature shown in Fig. 4 is the magnitude of the gap between the actual measured extent of carbonation (reference mode), which implies some passivation of the olivine surface, and the prediction without passivation. The sheer size of this gap demonstrates that overcoming the passivation problem is pivotal for development of the aqueous mineral carbonation process. Moreover, Fig. 4 indicates that, if no passivation phenomena occurred, $100 \%$ carbonation of olivine could be achieved with such grain sizes, using pure water as a solvent - i.e. without any additives - in about $5 \mathrm{~h}$.

\subsection{Robustness of the hybrid exfoliation/mineralisation process}

The five materials selected for this work were tested using the hybrid attrition-leaching protocol. Tests were carried out at

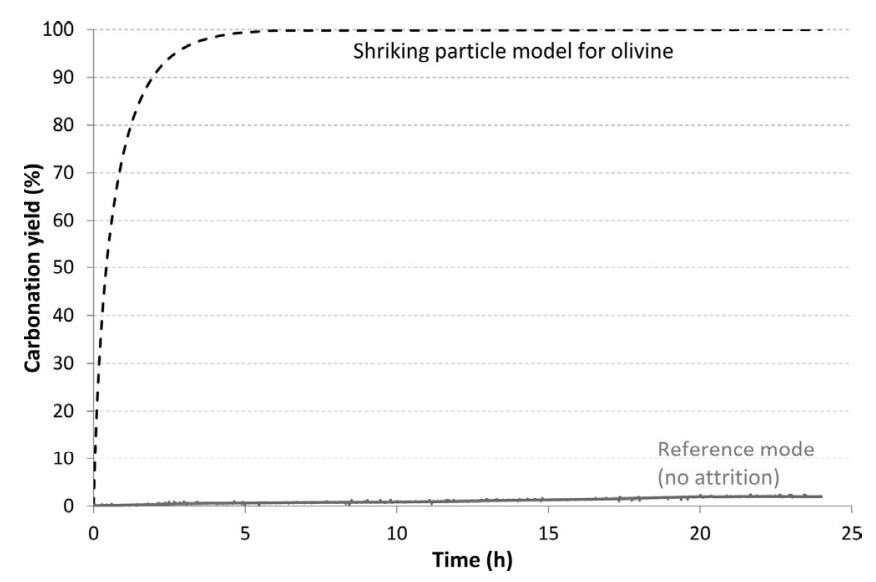

Fig. 4. Comparison between the best possible carbonation performance attainable, i.e. without surface passivation, and the reference mode performance (olivine $90 \mathrm{~g} \mathrm{~L}^{-1}, 180^{\circ} \mathrm{C}, 20$ bar of $\mathrm{CO}_{2}$ ) (Bodénan et al. [28]). 


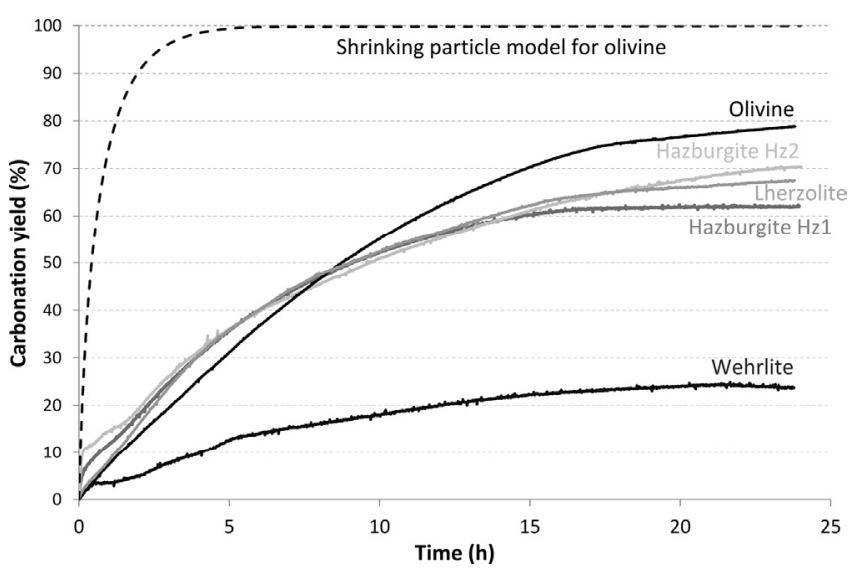

Fig. 5. Demonstration of the robustness of the hybrid mineral carbonation process, showing the hybrid process performance for all five materials investigated and the best achievable performance for olivine $\left(90 \mathrm{~g} \mathrm{~L}^{-1}, 180^{\circ} \mathrm{C}\right.$ and 20 bar of $\left.\mathrm{CO}_{2}\right)$ (Bodénan et al. [28]).

$180^{\circ} \mathrm{C}, 20$ bar of $\mathrm{CO}_{2}$ and $90 \mathrm{~g} \mathrm{~L}^{-1}$. Fig. 5 shows the hybrid process performance for all five materials, along with the best achievable performance for olivine given as reference. The results with olivine undergoing the hybrid process show that this protocol is able to bridge a significant portion of the gap between the performance measured without attrition and the best achievable performance, keeping in mind that the process itself is not optimised. Table 2 gives the final carbonation extents for all five materials, with and without hybrid exfoliation.

Lherzolite and harzburgite, which all contain a high amount of serpentinised materials, gave carbonation performance close to that of olivine. Of the five materials tested, only wehrlite yielded significantly lower carbonation extent, albeit significantly higher than that obtained without any grinding.

Emphasising that the test conditions were not optimized in any way with respect to solid concentration, attrition rate, bead size distribution or bead volume fraction, not to mention that the converted autoclave is not an actual attrition bead mill, the results that were obtained demonstrate the potential of the hybrid attritionleaching process, and its robustness with respect to variations in used materials to be processed. This latter feature is critical given the expectation that mineral carbonation should be able to process different materials equally. Material insensitivity cannot possibly be achieved reliably by any chemically based process.

In the liquid phase, only traces of iron were detected. Average extraction yields of silicium and magnesium in solution reached about $1.5 \%$ for both two-step and hybrid modes. In the reference experiments (without attrition), similar concentrations of Si were obtained, but significantly less $\mathrm{Mg}$ (less than half) as the result of the ore passivation. Note that for the $90 \mathrm{~g} \mathrm{~L}^{-1}$ olivine slurry, the shrinking particle model predicts that, after $24 \mathrm{~h}, 2.1 \%$ of the initial Si content would be in solution, $\mathrm{Mg}$ being completely converted into solid carbonate.

\subsection{Synergy between attrition grinding exfoliation and mineralisation processes}

One important question about the hybrid process concerns the nature and extent of the synergy between the exfoliation and mineralisation mechanisms. Table 2 , which shows that carbonation yield with the hybrid process is consistently higher than with the two-step process, proves the synergy between the two processes, hence their actual hybridisation.

Fig. 6 shows the carbonation yield curves with both processing modes for olivine, harzburgite, and lherzolite samples. The twostep mode yields consistently faster mineralisation kinetics at the start of the mineralisation step. This is explained by the finer particle size distribution from the first attrition only step of the two-step mode, as shown in Fig. 7. However, the hybrid mode mineralisation kinetics always exceeds that of the two-step within a few hours, giving $20 \%$ or more additional carbonation yield after $24 \mathrm{~h}$.

These measurements prove that there is an actual synergy between attrition grinding and mineralisation processes. This result rejects the argument put forward by Park and Fan that the effect observed by the ARC was due to particle size only.

Additional understanding was sought at the local particle scale, starting with the particle size distribution. Fig. 7 shows the size distribution of the different products for olivine sample. The similarity of PSD obtained at the end of the hybrid process and prior to carbonation in the two-step process confirms the previous statement. Nonetheless one part of the gap reduction between the experimental results and the theoretical ones must be attributed to size reduction.

Size distributions of final products are also similar in mean diameter, with a measured $d_{50}$ value of $7.0 \mu \mathrm{m}$ and $4.2 \mu \mathrm{m}$ for two-step and hybrid protocols respectively. The fineness of the final product is clearly dictated by the conditions used for the attrition grinding process, as reflected by the convergence between the product size distributions, notwithstanding the right tail of the two-step process product. However, analysis of the particles themselves shows radically different reaction products.

Fig. 8 displays characteristic features of the two-step and hybrid product particles.

The reaction product from the two-step mode is composed of large magnesite particles, which account for the mode to the right of the particle size distribution in Fig. 7, and unreacted olivine cores surrounded by the same passivating phyllosilicate layer found in experiments without attrition (cf. Fig. 1b). Note that this phyllosilicate may include chemical elements coming from the grinding media, explaining the slight differences between the carbonation kinetics observed when using alumina or zirconia beads (cf. Fig. 6a).

This reaction product is to be expected from a purely fine grinding effect. Indeed, the large particles of magnesite were allowed to grow to large sizes during the $24 \mathrm{~h}$ mineralisation only with the two-step protocol. Passivation of fine particles produced by the $24 \mathrm{~h}$ attrition grinding phase did occur, but the fineness of the feed

Table 2

Carbonation yield ${ }^{*}$ after $24 \mathrm{~h}$ for the five ores selected $\left(90 \mathrm{~g} \mathrm{~L}^{-1}\right)$, for the three test protocols at $T=180{ }^{\circ} \mathrm{C}, \mathrm{PCO}_{2}=20$ bar, and with alumina grinding beads unless otherwise specified.

\begin{tabular}{|c|c|c|c|}
\hline & Reference mode (no grinding media) & Two-step mode & Hybrid mode \\
\hline Olivine (Magnolite) & $2.0 \%\left(\mathrm{CO}_{2}\right.$ consumption $)$ & $46.7 \%$ (38.0\% with $\left.\mathrm{ZrO}_{2}\right)$ & 78.8\% (repetition: $76.7 \%$ ) \\
\hline Harzburgite $\mathrm{Hz} 1$ & $7.8 \%\left(\mathrm{CO}_{2}\right.$ consumption $)$ & $35.8 \%$ with $\mathrm{ZrO}_{2}$ & $62.1 \%$ \\
\hline Harzburgite $\mathrm{Hz2}$ & $6.3 \%$ & $34.0 \%$ with $\mathrm{ZrO}_{2}$ & $70.4 \%$ \\
\hline Lherzolite & $0.6 \%\left(\mathrm{CO}_{2}\right.$ consumption $)$ & $45.8 \%$ & $67.5 \%$ \\
\hline Wehrlite & non detectable & $17.2 \%$ with $\mathrm{ZrO}_{2}$ (repetition: $19.2 \%$ ) & $23.7 \%$ \\
\hline
\end{tabular}

Calculated from $\mathrm{C}$ analysis of solids (unless otherwise mentioned). 

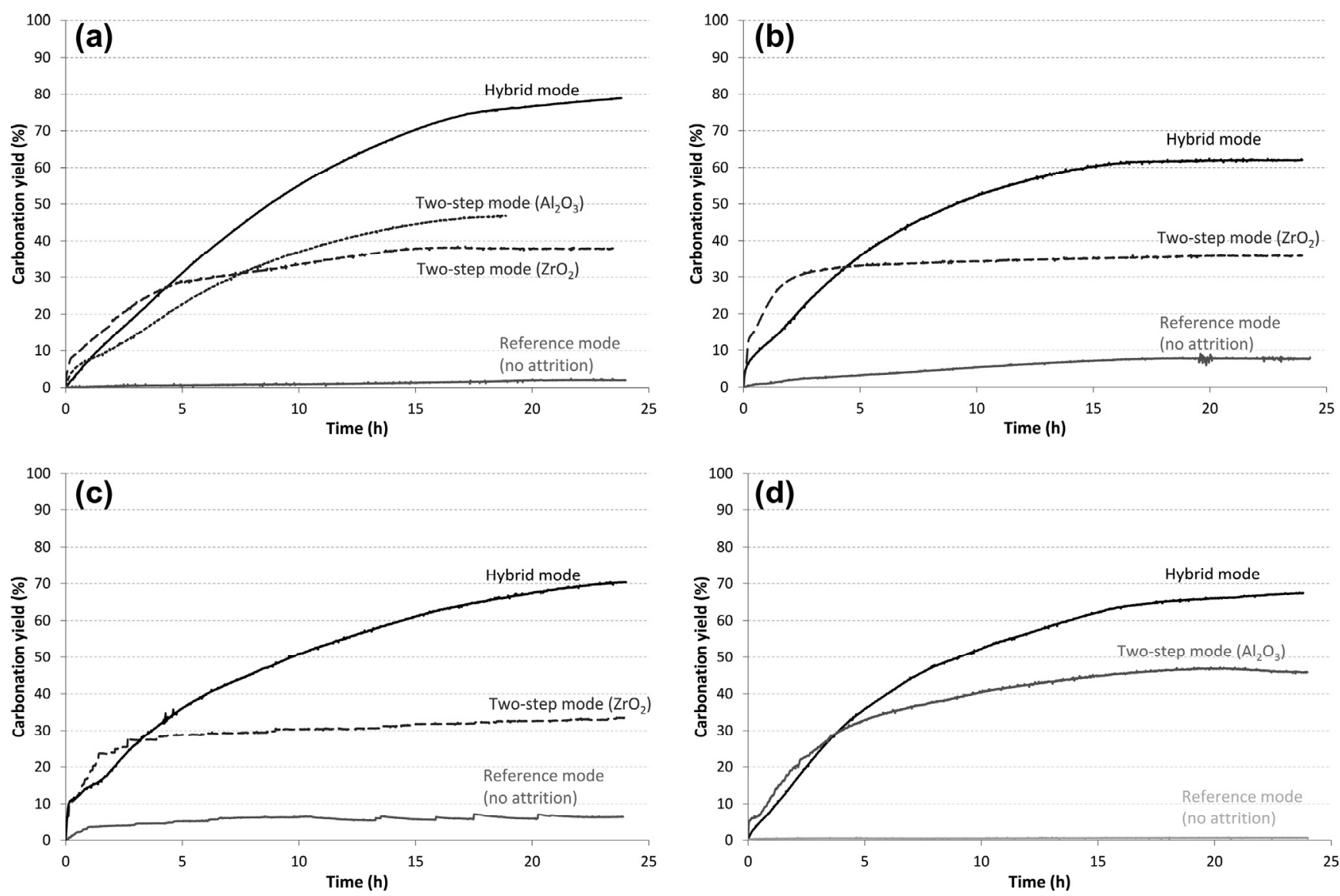

Fig. 6. Carbonation yield curves for the reference, two-step and hybrid processes (slurry concentration $=90 \mathrm{~g} \mathrm{~L}^{-1}, T=180{ }^{\circ} \mathrm{C}, \mathrm{PCO}_{2}=20 \mathrm{bar}$, grinding bead type given in brackets for two-step mode): (a) olivine; (b) harzburgite Hz1; (c) harzburgite Hz2; (d) lherzolite.

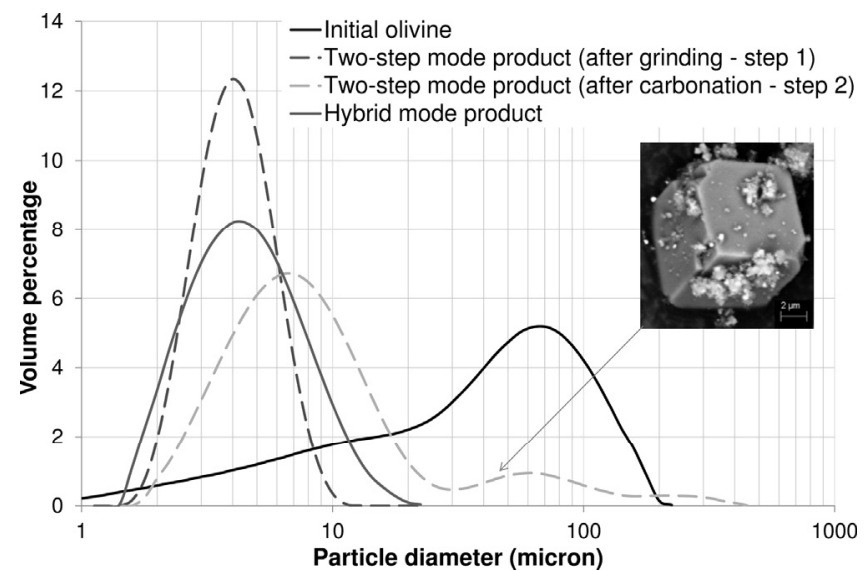

Fig. 7. Particle size distribution of the feed and reaction products for the olivine sample ( $90 \mathrm{~g} \mathrm{~L}^{-1}, 180{ }^{\circ} \mathrm{C}$ and 20 bar of $\mathrm{CO}_{2}$, alumina grinding beads); insert is an example of large magnesite particles obtained in two-step mode.

particles to the mineralisation step, with a $d_{50}$ of $3.8 \mu \mathrm{m}$, yielded the measured increase in carbonation.

The hybrid product particles, with $d_{50}$ about $4 \mu \mathrm{m}$ (see Fig. 7), are actually aggregates that are constituted of particles a few tens of nanometers in size. These aggregates contain carbonates, amorphous silica particles or silicate particles with very low magnesium content and alumina fragments from grinding bead wear.

A significant observation from Fig. $8 b$ is the absence of a fibrous phyllosilicate layer covering residual olivine grains and that was invariably observed with the two-step process. This confirms, at the particle scale, the actual synergy between exfoliation and reaction in the hybrid process. Indeed, this shows that the hybrid process successfully prevents the formation of the passivation layers whose formation controls the performance of the direct aqueous mineral carbonation. We also note the scarcity of residual olivine particles in the hybrid process, because olivine has reacted almost fully thanks to the continuous elimination of passivation layers, leaving behind amorphous silica containing traces of magnesium and aluminum.

\section{Discussion}

The results and analyses presented in the previous section have demonstrated the soundness of the hybrid mineral carbonation process, defined previously as the conduction of direct aqueous mineral carbonation under attrition conditions. The operating conditions tested within this work were chosen by analogy with those of typical stirred bead mills, which are proven units dedicated to attrition. However, for the purpose of the hybrid process under consideration, the margin for performance improvement is expected to be significant.

Assessment of the potential of the hybrid process is discussed hereafter from both life cycle analysis and process viewpoints. One issue of importance concerning the hybrid mineral carbonation process concerns its technical feasibility for large scale operations. Large scale stirred bead mills being a mature technology, as reflected by their current popularity in the metalliferous mining sector, the feasibility of the hybrid mineral carbonation process is deemed very much achievable. Nonetheless, large scale stirred 

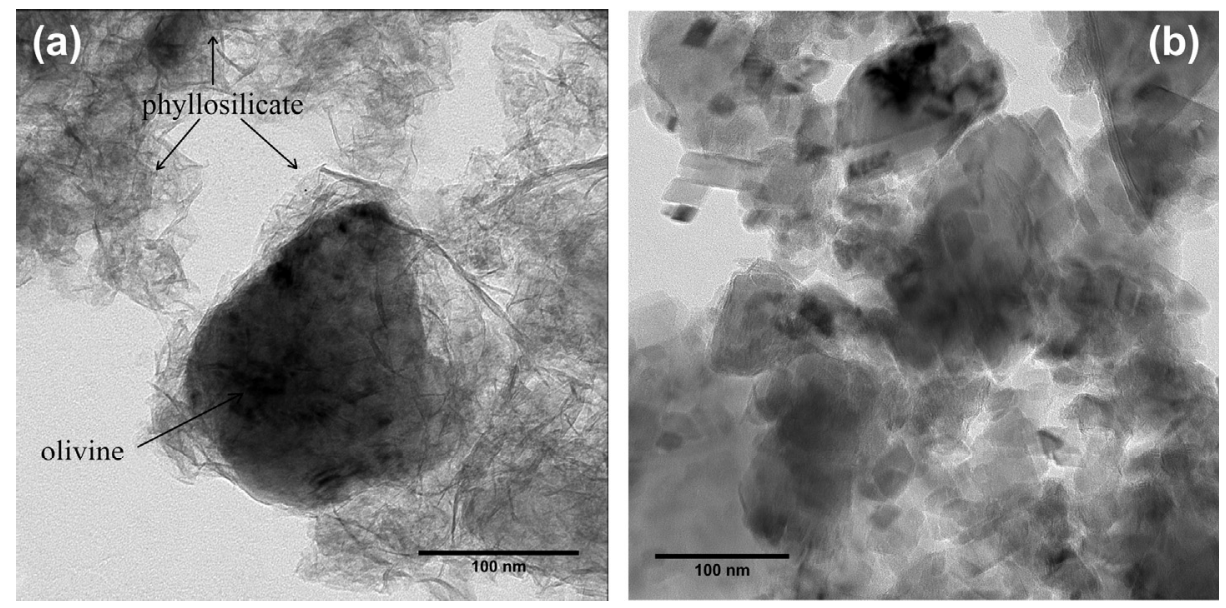

Fig. 8. TEM images of reaction products (olivine $90 \mathrm{~g} \mathrm{~L}^{-1}, 180{ }^{\circ} \mathrm{C}, 20$ bar of $\mathrm{CO}_{2}$ ): (a) from two-step mode (24 h of reaction following $24 \mathrm{~h}$ of attrition under ambient conditions) showing phyllosilicate layer covering residual olivine particle; (b) from hybrid leaching-attrition mode (24 h) showing magnesite particles of tens of nanometers.

bead mills capable of operating under pressures and temperatures demanded by the mineralisation process are not yet commercialised, and existing machinery will have to be adapted to meet the requirements of the hybrid mineral carbonation process. The necessary adaptations however, which concern liner and agitation internals, gas dispersion and solid dynamic classification are all technically feasible. The scalability of such attrition grinding mills from models a few litres in volume, which simplifies considerably operating conditions determination and sizing of large scale systems, is a major asset for industrialisation of the hybrid mineral carbonation process.

\subsection{Preliminary LCA analysis of the hybrid aqueous mineral carbonation process}

The experimental results presented in this paper were used to perform an LCA analysis of the hybrid process, in an attempt to assess its environmental performance. To this end, the following functional unit was used to produce $1 \mathrm{MWh}$ of electrical energy with a coal power plant. This analysis was performed to position the environmental ranking of the hybrid process against two scenarios for the functional unit selected, namely without $\mathrm{CO}_{2}$ capture, with $\mathrm{CO}_{2}$ capture and geosequestration, and with $\mathrm{CO}_{2}$ capture and ex-situ mineral carbonation using the hybrid process, and to identify possible means of improving the environmental footprint of the hybrid process.

For the hybrid process, the following process parameters were accounted for in the analysis:

- The mass fraction of $\mathrm{Mg}(+\mathrm{Ca})$ in the ore, and the extent of conversion of $\mathrm{Mg}(+\mathrm{Ca})$ obtained at the end of the hybrid process, defined as the molar fraction converted to carbonates $-\mathrm{MgCO}_{3}\left(\right.$ and $\left.\mathrm{CaCO}_{3}\right)$. Both parameters yield the amount of ore necessary to store one ton of $\mathrm{CO}_{2}$. Under the most favourable conditions of the hybrid process, it was estimated that 2.47 tons of olivine were necessary to store 1 ton of $\mathrm{CO}_{2}$.

- The slurry solid concentration. This variable was used to determine the energy necessary to heat up the water, relative to the amount of processed ore.

- The initial PSD of the ore, as extracted, and the PSD of the ore after crushing and grinding before it is used in the hybrid process. This information yielded estimation of the energy used for comminution using Bond's formula, using a realistic Bond work index value of $13 \mathrm{kWh} / \mathrm{t}$.
- The PSD of the material at the end of the hybrid process. This parameter was used to assess the amount of energy expended by the mechanical exfoliation process.

- The slurry temperature and the efficiency of the heat exchanger used to recycle the water through the process. This information gave the energy necessary for heating up the water, the $\mathrm{CO}_{2}$ and the ore. The heat capacity of $\mathrm{Mg}_{2} \mathrm{SiO}_{4}$ was used in the calculations.

- The $\mathrm{CO}_{2}$ pressure. As the hybrid process was operated at a $\mathrm{CO}_{2}$ partial pressure of $20 \mathrm{bar}$, the LCA analysis considered a transport of $\mathrm{CO}_{2}$ through a $380 \mathrm{~mm}$ diameter pipeline at a pressure of 20 bar. A distance of $300 \mathrm{~km}$ was assumed between the source $\mathrm{CO}_{2}$ (power station and MEA $\mathrm{CO}_{2}$ capture plant) and the mineral carbonation plant, which eliminated the need for additional compression stages along the pipeline to compensate for head loss. The energy required to pressurize the $\mathrm{CO}_{2}$ to the operating pressure of the hybrid process, namely $20 \mathrm{bar}$, was also accounted for in the analysis.

The following environmental indicators were used to quantify the environmental performance of the hybrid process:

- related to resource consumption: natural resource depletion and non-renewable primary energy consumption,

- related to global warming: climate change,

- related to air pollution: terrestrial acidification and photochemical oxidation.

These indicators were deemed most reliable and relevant for the purpose of the work.

Results reported here for the hybrid process were those obtained with the olivine ore under the following operating conditions:

- The ore was assumed to be crushed from $1 \mathrm{~cm}$ to $1 \mathrm{~mm}$, then dry-milled from $1 \mathrm{~mm}$ to $100 \mu \mathrm{m}$.

- Notwithstanding the marginal effect of solids concentration in the range $90-250 \mathrm{~g} \mathrm{~L}^{-1}$ on reaction rate and carbonation yield (cf. Section 4.2.), the latter was set to the best value measured in this study (about 79\%), corresponding to olivine processing at $180^{\circ} \mathrm{C}$ under 20 bar of $\mathrm{CO}_{2}$.

- Solids concentration was set to $250 \mathrm{~g} \mathrm{~L}^{-1}$.

These conditions, particularly with respect to the solids concentration, are favourable in terms of water and energy usage. 
Table 3 gives the overall LCA analysis results for the hybrid process, giving the overall impacts, and the relative weight of the coal power station, $\mathrm{CO}_{2}$ capture, $\mathrm{CO}_{2}$ transport and hybrid process.

While the analysis shows that $\mathrm{CO}_{2}$ transport has a negligible impact on the overall process impact, it indicates that the hybrid process has an environmental impact comparable to that of the coal power station plus $\mathrm{CO}_{2}$ capture system on those LCA criteria not associated with resource consumption. For criteria associated with resource consumption, the hybrid process has an environmental impact comparable with the $\mathrm{CO}_{2}$ capture process used to produce pure $\mathrm{CO}_{2}$ stream from the power station exhaust gases. The $\mathrm{CO}_{2}$ capture is included in the LCA analysis as the experiments reported here with the hybrid process were carried out using pure $\mathrm{CO}_{2}$. The impact indicator values show that the hybrid process should be tested using dilute $\mathrm{CO}_{2}$, which could possibly yield a lesser dependency on $\mathrm{CO}_{2}$ capture, hence a reduced overall environmental impact.

Table 4 compares the overall LCA results for the functional unit:

- without $\mathrm{CO}_{2}$ capture

- with $\mathrm{CO}_{2}$ capture and geological storage

- with $\mathrm{CO}_{2}$ capture and the hybrid process.

The positive effect of capture and storage, whether geological or by mineralisation, on the climate change indicator confirms that both solutions meet their objective of reducing the net greenhouse gas emissions. Both $\mathrm{CO}_{2}$ mitigation options however have negative impacts on most of the other LCA indicators selected, the hybrid process having at least twice the impact of the geological storage scenario. The impact of the hybrid process would possibly be further reduced through a number of levers, including the use of dilute $\mathrm{CO}_{2}$ gas streams, and the beneficiation of reaction products, possibly in the construction sector.

\subsection{Process optimization}

There are a number of possibilities for optimizing the hybrid process to be explored further, following the guidelines set by the preceding LCA analysis. Complementary experiments were performed to test the scope for reducing temperature and increasing slurry solid concentration, bearing in mind that both these operating conditions can be changed.

Stirred bead mills can be operated at high solid concentration, say $40 \mathrm{wt} \%$ and more with metalliferous ores. Fig. 9 shows the variation in performance of the hybrid mineralisation process with the

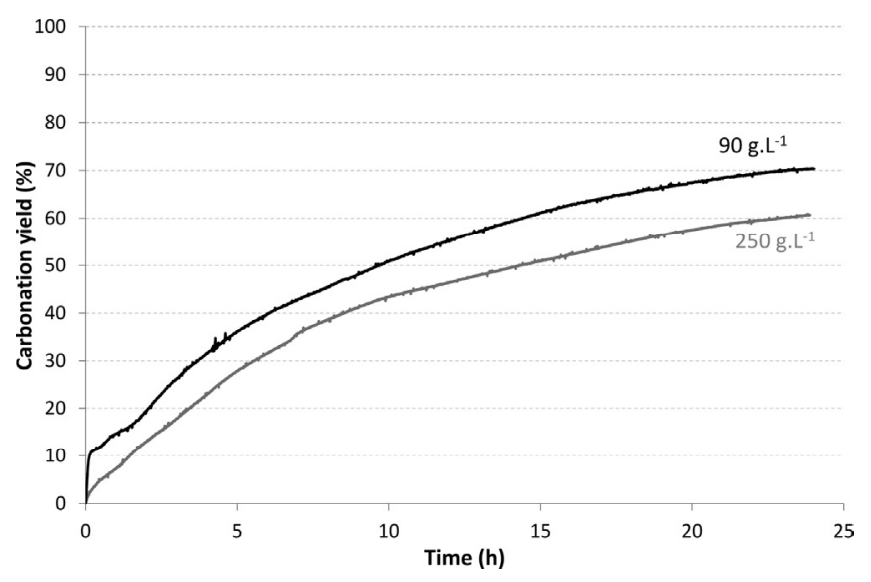

Fig. 9. Hybrid mineralisation process performance for harzburgite $\mathrm{Hz} 2$ at $90 \mathrm{~g} \mathrm{~L}^{-1}$ and $250 \mathrm{~g} \mathrm{~L}^{-1}\left(180^{\circ} \mathrm{C}\right.$ and 20 bar of $\left.\mathrm{CO}_{2}\right)$.

harzburgite sample $\mathrm{Hz} 2$ between $90 \mathrm{~g} \mathrm{~L}^{-1}$ and $250 \mathrm{~g} \mathrm{~L}^{-1}$. After $24 \mathrm{~h}$, these conditions gave a carbonation yield of $70.4 \%$ and $60.7 \%$, respectively, recalling that the relative uncertainty in final carbon contents related to material inhomogeneity is less than $5 \%$ (cf. Section 2.5.). The reduction in performance with the highest solids concentration in the test is deemed related to the difficulty of our stirred bead mill set-up, which is a modified autoclave, to provide efficient agitation considering the mechanical limitations of the stirring mechanism.

Considering that the process used the same operating conditions in both cases, this result suggests that the hybrid mineralisation process can potentially be operated at the highest slurry concentration accepted by industrial stirred bead mills. As shown in the LCA analysis, this is an important practical issue, since going from $9 \mathrm{wt} \%$ to $40 \mathrm{wt} \%$ solids means that water required for the process is reduced by more than $30 \%$, and so the energy required to maintain the slurry temperature at that required by the mineralisation process.

Considering the nature of the passivation layer and its associated transport properties [39], a temperature of $180^{\circ} \mathrm{C}$ appears to be about the ideal temperature. Nonetheless, the hybrid mineralisation process, by nature, circumvents the passivation layer issue. The question is about its overall efficiency in relation with the properties of the passivation layers. Providing this question with answers is premature, development work is required using

Table 3

LCA results for the $\mathrm{CO}_{2}$ mitigation scenario using the hybrid process.

\begin{tabular}{|c|c|c|c|c|c|c|}
\hline Environmental impact indicators & Units & Total & Coal power station & MEA CO ${ }_{2}$ capture & Pipeline transport of $\mathrm{CO}_{2}$ & Hybrid process \\
\hline Natural resource depletion & kg Sb eq. & 12 & $55.39 \%$ & $25.63 \%$ & $0.05 \%$ & $19.01 \%$ \\
\hline Non-renewable primary energy consumption & Primary MJ & 20,942 & $47.70 \%$ & $22.01 \%$ & $0.06 \%$ & $30.23 \%$ \\
\hline Climate change & $\mathrm{kg} \mathrm{CO}_{2}$ eq. & 608 & $151.60 \%$ & $-102.8 \%$ & $0.14 \%$ & $51.17 \%$ \\
\hline Terrestrial acidification & $\mathrm{kg} \mathrm{SO}_{2}$ eq. & 2.5 & $65.23 \%$ & $-17.10 \%$ & $0.16 \%$ & $51.91 \%$ \\
\hline Photochemical oxidation & kg NMVOC eq. & 1.99 & $48.99 \%$ & $17.98 \%$ & $0.30 \%$ & $32.73 \%$ \\
\hline
\end{tabular}

Table 4

Selected LCA criteria for the three selected scenarios.

\begin{tabular}{|c|c|c|c|c|}
\hline Environmental impact indicators & Units & Without $\mathrm{CO}_{2}$ capture & $\begin{array}{l}\text { With } \mathrm{CO}_{2} \text { capture and } \\
\text { geological storage (\%) }\end{array}$ & $\begin{array}{l}\text { With } \mathrm{CO}_{2} \text { capture and } \\
\text { the hybrid process (\%) }\end{array}$ \\
\hline Natural resource depletion & kg Sb eq. & 6.7 & +46 & +79 \\
\hline Non-renewable primary energy consumption & Primary MJ & 9990 & +47 & +110 \\
\hline Climate change & $\mathrm{kg} \mathrm{CO}_{2}$ eq. & 923 & -68 & -34 \\
\hline Terrestrial acidification & $\mathrm{kg} \mathrm{SO}{ }_{2}$ eq. & 1.64 & -26 & +52 \\
\hline Photochemical oxidation & kg NMVOC eq. & 0.973 & +38 & +105 \\
\hline
\end{tabular}




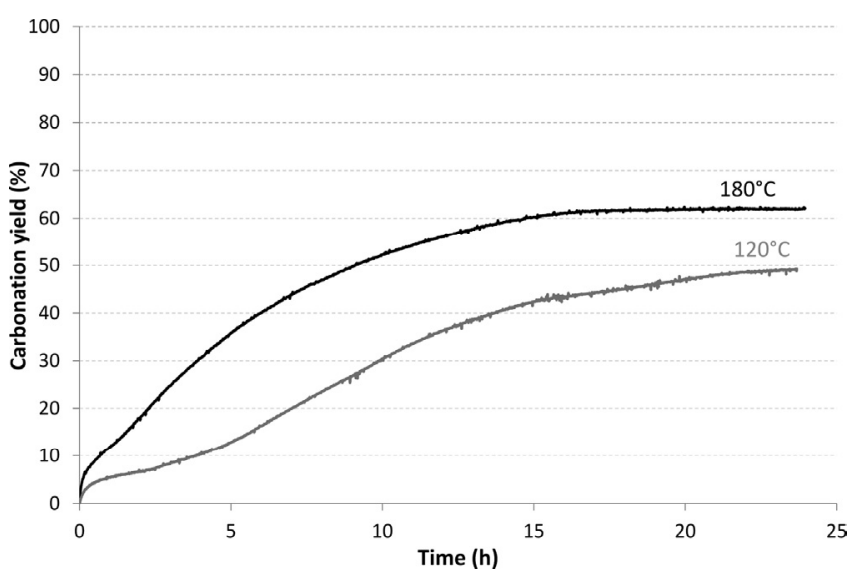

Fig. 10. Hybrid mineralisation process performance for $90 \mathrm{~g} \mathrm{~L}^{-1} \mathrm{~Hz} 1$ slurry at $180^{\circ} \mathrm{C}$ and $120^{\circ} \mathrm{C}\left(20\right.$ bar of $\left.\mathrm{CO}_{2}\right)$.

industrially designed stirred bead mills. Notwithstanding, Fig. 10 shows the variation in performance of the hybrid mineralisation process with the harzburgite $\mathrm{Hz} 1$ sample at $180^{\circ} \mathrm{C}$ and $120^{\circ} \mathrm{C}$. After $24 \mathrm{~h}$, these conditions gave carbonation yields of $62.1 \%$ and $49.2 \%$, respectively.

Whether the drop in performance is associated with a greater difficulty of the attrition grinding process to exfoliate the passivation layer that forms at $120^{\circ} \mathrm{C}$, it is premature to say; however it is possible. At any rate, the conversion of the harzburgite sample at $120^{\circ} \mathrm{C}$ is significant, and additional research is necessary to determine the best operating temperature from an overall process performance analysis.

As discussed previously, there is significant scope for enhancing the performance of the hybrid mineralisation process over those reported in this work, which already stand amongst the best ones measured to date. For instance use of the $1 \mathrm{M} \mathrm{NaCl}+0.64 \mathrm{M}$ $\mathrm{NaHCO}_{3}$ solution (cf. Section 1.2.) instead of water still improves the carbonation yield which reaches $70 \%$ within $5 \mathrm{~h}$ ( $87 \%$ in $24 \mathrm{~h}$ ) in the case of $90 \mathrm{~g} \mathrm{~L}^{-1}$ olivine slurry at $180^{\circ} \mathrm{C}$.

Besides all the positive attributes of this technology which have been discussed earlier, important performance gains are expected from operating the hybrid mineralisation process in a continuous mode, for which closed and open loop configuration should be tested.

\section{Conclusions}

As one of the most promising solution to $\mathrm{CO}_{2}$ mitigation, mineral carbonation remains an important area of research and development. In this paper, an innovative process is proposed for aqueous mineral carbonation. The proposed solution is referred to as hybrid process as it merges the aqueous mineral carbonation reactions with a continuous attrition process carried out in a stirred bead mill. The attrition process permits continuous exfoliation of passivation layers that form during the leaching of magnesium silicates, and hence overcomes the most important limiting factor for development of an efficient aqueous mineral carbonation process. It is found that the process shows marginal sensitivity to ore type and operating conditions, contrary to chemical-based processes whose performance is highly dependent on the nature of the ore and the geochemistry of the reactive system. Careful analyses of reaction products reveal that there is an actual synergy between the mechanical exfoliation of the reactive particle and mineral carbonation processes. Without optimization of the process conditions, the hybrid process consistently yields high carbonation yields for serpentinised ores with reasonable kinetics. Through the hybrid process, all the reactive ore is consumed, leaving a mixture of fine particles of innocuous carbonate and siliceous particles.

It is argued that the margin for improvement of this process is significant. Indeed, a number of operating conditions can be modified, with a strong likelihood of producing improved performance. Using an actual stirred bead mill in a continuous circuit, as opposed to the autoclave used in batch mode in this work, will provide more efficient conditions for attrition and mineralisation reactions. The capacity of stirred mills to process mining scale throughputs, and their ease of scale-up are very important assets of the proposed hybrid mineralisation process for industrial scale applications. A number of other conditions can be investigated, all of which can contribute to improving the performance of the proposed process, in terms of kinetics and net energy consumption. These include, without specific order, lowering the partial pressure of $\mathrm{CO}_{2}$, operating with diluted flue gases instead of pure $\mathrm{CO}_{2}$, optimizing the attrition conditions, such as operating the stirred mill in semi or complete autogenous mode, reducing the net energy balance of the process by reducing the amount of process water through increasing the solid concentration, and lowering the operating temperature.

This process is not without pending questions however, the main one concerning the handling and beneficiation of the reaction products. As found experimentally, the process produces a suspension bearing fine carbonate and siliceous particles with a mean size around $5 \mu \mathrm{m}$. These ca. $5 \mu \mathrm{m}$ aggregates are themselves constituted of tens of nanometers sized individual grains. Product handling demands a dewatering step for process water recovery. Centrifugal tests used for product characterisation have indicated that the particles have good settling properties, hence solid-liquid separation is not deemed to be an issue. The beneficiation of the product however is very much an open question. Physical separation of carbonate and siliceous particles seems unlikely, so that beneficiation should target the product mixture as a whole. The chemical content of the product could make it eligible for making magnesium cements, however dedicated research is necessary to test the possibilities of beneficiating the hybrid process products in the construction sector.

\section{Acknowledgements}

This research work was conducted as part of B. Bonfils' Ph.D. and post-doctoral fellowship, which were supported by the French National Research Agency under the Carmex Project No. ANR08-PCO2-002 and the oil and gas company TOTAL. The authors also thank Jean-Louis Labat, Ignace Coghe, Lahcen Farhi (ST, LGC Toulouse) for their technical support on the set-up, Marie-Line de Solan Bethmale, Christine Rey-Rouch (SAP, LGC) and Alain Moreau (LCC Toulouse) for solution and material characterizations.

\section{References}

[1] W. Seifritz, CO $\mathrm{CO}_{2}$ disposal by means of silicates, Nature 345 (1990) 486 .

[2] K.S. Lackner, D.P. Butt, C.H. Wendt, Progress on binding $\mathrm{CO}_{2}$ in mineral substrates, Energy Convers. Manage. 38 (1997) S259-S264.

[3] G.E. Hilley, S. Porder, A framework for predicting global silicate weathering and $\mathrm{CO}_{2}$ drawdown rates over geologic time-scales, Proc. Natl. Acad. Sci. U.S.A. 105 (2008) 16855-16859.

[4] D.J. Fauth, Y. Soong, C.M. White, Carbon sequestration utilizing industrial solid residues, Fuel Chem. Div. 47 (2002) 37-38.

[5] W.J.J. Huijgen, R.N.J. Comans, Carbonation of steel slags for $\mathrm{CO}_{2}$ sequestration: leaching of products and reaction mechanisms, Environ. Sci. Technol. 40 (2006) 2790-2796.

[6] V.S. Yadav, M. Prasad, J. Khan, S.S. Amritphale, M. Singh, C.B. Raju, Sequestration of carbon dioxide $\left(\mathrm{CO}_{2}\right)$ using red mud, J. Hazard. Mater. 176 (2010) 1044-1050.

[7] J. Vogeli, D.L. Reid, M. Becker, J. Broadhurst, J.P. Franzidis, Investigation of the potential for mineral carbonation of PGM tailings in South Africa, Miner. Eng. 24 (2011) 1348-1356. 
[8] G.P. Assima, F. Larachi, G. Beaudoin, J. Molson, Dynamics of carbon dioxide uptake in chrysotile mining residues - effect of mineralogy and liquid saturation, Int. J. Greenhouse Gas Control 12 (2013) 124-135.

[9] G. Montes-Hernandez, R. Pérez-López, F. Renard, J.M. Nieto, L. Charlet, Mineral sequestration of $\mathrm{CO}_{2}$ by aqueous carbonation of coal combustion fly-ash, J Hazard. Mater. 161 (2009) 1347-1354.

[10] C. De Vito, S. Mignardi, V. Ferrini, R.F. Martin, Reject brines from desalination as possible sources for environmental technologies, in: R.Y. Ning (Ed.), Expanding Issues in Desalination, InTech, 2011, http://dx.doi.org/10.5772/ 20302. ISBN: 978-953-307-624-9.

[11] A. Sanna, M. Uibu, G. Caramanna, R. Kuusik, M.M. Maroto-Valer, A review of mineral carbonation technologies to sequester $\mathrm{CO}_{2}$, Chem. Soc. Rev. (2014) http://dx.doi.org/10.1039/C4CS00035H.

[12] M. Ghoorah, R.D. Balucan, E.M. Kennedy, B.Z. Dlugogorski, Selection of acid for weak acid processing of Australian wollasnotine for mineralisation of $\mathrm{CO}_{2}$, proceedings ACEME 2013, Leuven, Belgium.

[13] B. Dlugogorski, E. Kennedy, J. Bailey, M. Dawe, Carbon Mineralisation, <http:// www.resources.nsw.gov.au/_data/assets/pdf_file/0007/343456 Dlugogorski_Carbon-mineralisation.pdf> (accessed July 2013).

[14] F. Doucet, Scoping Study on $\mathrm{CO}_{2}$ Mineralization Technologies, Report No. CGS2011-007, South African Centre for Carbon Capture and Storage, 2011.

[15] W.K. O'Connor, D.C. Dahlin, D.N. Nielsen, G.E. Rush, R.P. Walters, P.C. Turner Carbon dioxide sequestration by direct mineral carbonation: results from recent studies and current status. DOE/ARC-2001-029, Albany Research Center, 2001.

[16] L. Penner, W.K. O'Connor, D.C. Dahlin, S. Gerdemann, G.E. Rush, Minera Carbonation: Energy Costs of Pretreatment Options and Insights Gained from Flow Loop Reaction Studies, US DOE, DOE/ARC-TR-04-042, 2004.

[17] M.J. McKelvy, A.V.G. Chizmeshya, K. Squires, R.W. Carpenter, H. Béarat, A novel approach to mineral carbonation: enhancing carbonation while avoiding mineral pretreatment process cost, Arizona State University, Report DE-FG2604NT42124, 2006.

[18] A.V.G. Chizmeshya, M.J. McKelvy, K. Squires, R.W. Carpenter, H. Béarat, A nove approach to mineral carbonation: enhancing carbonation while avoiding mineral pretreatment cost, DOE: DE-FG26-04NT42124 final report, 2007.

[19] H. Béarat, J.M. McKelvy, A.V.G. Chizmeshya, D. Gormley, R. Nunez, R.W Carpenter, K. Squires, G. Wolf, Carbon sequestration via aqueous olivine mineral carbonation: role of passivating layer formation, Environ. Sci. Technol. 40 (2006) 4802-4808.

[20] M.A. Velbel, Formation of protective surface layers during silicate-minera weathering under well-leached, oxidizing conditions, Am. Mineral. 78 (1993) 405-414.

[21] R. Hellman, R. Wirth, D. Daval, J.P. Barnes, J.M. Penisson, D. Tisserand, T. Epicier, B. Florin, R.L. Hervig, Unifying natural and laboratory chemical weathering with interfacial dissolution-reprecipitation: a study based on the nanometer-scale chemistry of fluid-silicate interfaces, Chem. Geol. 294295 (2012) 203-216.

[22] D. Daval, O. Sissmann, N. Menguy, G.D. Saldi, F. Guyot, I. Martinez, J. Corvisier B. Garcia, I. Machouk, K.G. Gnauss, R. Hellmann, Influence of amorphous silica layer formation on the dissolution rate of olivine at $90{ }^{\circ} \mathrm{C}$ and elevated $\mathrm{pCO}_{2}$, Chem. Geol. 284 (2011) 193-209.

[23] D. Daval, R. Hellmann, I. Martinez, S. Gangloff, F. Guyot, Lizardite serpentine dissolution kinetics as a function of $\mathrm{pH}$ and temperature, including effects of elevated $\mathrm{pCO}_{2}$, Chem. Geol. 351 (2013) 245-256.

[24] J. Schott, R.A. Berner, X-ray photoelectron studies of the mechanism of iron silicate dissolution during weathering, Geochim. Cosmochim. Acta 47 (1983) 2233-2240.

[25] F. Bodénan, F. Bourgeois, C. Petiot, T. Augé, B. Bonfils, C. Julcour-Lebigue, F. Guyot, A. Boukary, J. Tremosa, A. Lassin, E.C. Gaucher, P. Chiquet, Ex situ mineral carbonation for $\mathrm{CO}_{2}$ mitigation: Evaluation of mining waste resources, aqueous carbonation processability and life cycle assessment (Carmex project), Miner. Eng. 59 (2014) 52-63.

[26] A.H. Park, R. Jadhav, L.S. Fan, $\mathrm{CO}_{2}$ mineral sequestration: chemically enhanced aqueous carbonation of serpentine, Can. J. Chem. Eng. 81 (2003) 885-890.

[27] A.H. Park, L.S. Fan, $\mathrm{CO}_{2}$ mineral sequestration: physically activated dissolution of serpentine and pH swing process, Chem. Eng. Sci. 59 (2004) 5241-5247.

[28] A.H. Park, Carbon dioxide sequestration: chemical and physical activation of aqueous carbonation of Mg-bearing minerals and $\mathrm{pH}$ swing process (PhD dissertation), The Ohio State University, 2005.

[29] A.H. Park, L.S. Fan, Carbon dioxide sequestration using alkaline earth metalbearing minerals, US 2005/0180910 A1, 2005.

[30] L. Penner, W.K. O'Connor, S. Gerdemann, D.C. Dahlin, Mineralization Strategies for Carbon Dioxide Sequestration, proceedings 20th Annual International Pittsburgh Coal Conference, 2003, pp. 819-830.

[31] A. Jankovic, W. Valery, D. La Rosa, Fine Grinding in the Australian Mining Industry, proceedings RAMM 2003, Penang, Malaysia.

[32] N.W. Johnson, Review of Existing Eco-efficient Comminution Devices, The Coalition for Eco-Efficient Comminution (CEEC) Review paper, 2006.

[33] C. Rule, H. de Waal, IsaMillTM design improvements and operational performance at Anglo Platinum, proceedings MetPlant 2011, Perth, Australia, pp. 176-192.

[34] W.J.J. Huijgen, G.J. Witkamp, R.N.J. Comans, Mechanisms of aqueous wollastonite carbonation as a possible $\mathrm{CO}_{2}$ sequestration process, Chem. Eng. Sci. 61 (2006) 4242-4251.

[35] S.C. Krevor, K.S. Lackner, Enhancing serpentine dissolution kinetics for mineral carbon dioxide sequestration, Int. J. Greenhouse Gas Control 5 (2011) 10731080.

[36] V. Prigiobbe, M. Mazzotti, Dissolution of olivine in the presence of oxalate, citrate, and $\mathrm{CO}_{2}$ at $90^{\circ} \mathrm{C}$ and $120^{\circ} \mathrm{C}$, Chem. Eng. Sci. 66 (2011) 6544-6554.

[37] J. Van der Lee, Reactive transport modelling with HYTEC, User's Guide Nr. LHM/RD/05/30, Ecole des Mines de Paris, Fontainebleau, France, 2007.

[38] B. Bonfils, C. Julcour-Lebigue, F. Guyot, F. Bodénan, P. Chiquet, F. Bourgeois, Comprehensive analysis of direct aqueous mineral carbonation using dissolution enhancing organic additives, Int. J. Greenhouse Gas Control 9 (2012) 334-346.

[39] O. Sissman, Séquestration minérale du $\mathrm{CO}_{2}$ dans les basaltes et les roches ultrabasiques: impact des phases secondaires silicatées sur le processus de carbonatation (PhD dissertation), IPGP, France, 2013. 